\title{
Effect of Boron Addition on the Microstructure of Hot-deformed Ti-added Interstitial Free Steel
}

\author{
Nobuhiro TSUJI, Yukihiro MATSUBARA, ") Tetsuo SAKAl and Yoshihiro SAITO
}

Department of Materials Science and Engineering, Faculty of Engineering, Osaka University, Yamadaoka, Suita, Osaka-fu, 565 Japan. E-mail: tsuji@mat.eng.osaka-u.ac.jp 565 Japan.

1) Graduate Student, Osaka University, Yamadaoka, Suita, Osaka-fu,

(Received on February 10, 1997; accepted in final form on April 11, 1997)

\begin{abstract}
Effect of boron (B) addition and hot-deformation on microstructure of ferrite was studied using Ti-added interstitial free (IF) steels containing different amount of $B$. It was clarified that bainitic ferrite having typically lath or plate morphology with high dislocation density can be obtained also in plain IF steels by rapid cooling from austenite region. B addition largely affected the austenite-ferrite transformation and the amount of bainitic ferrite increased with increasing B content. Hot-deformation of austenite enhanced the transformation to polygonal or quasi-polygonal ferrite, resulting in decrease of bainitic ferrite. Interrupting compression tests indicated that enhanced transformation by hot-deformation is mainly due to grain refinement of austenite by recrystallization after hot-deformation. The cooling rate after hot-deformation produced the reversed effect of $B$ on grain size of polygonal or quasi-polygonal ferrite. Ferrite grain size slightly decreased with increasing $B$ content in the case of relatively large cooling rate. When the materials were cooled slowly after hot-deformation, on the other hand, the ferrite grain size increased with increasing B content. The coarse ferrite in B-bearing steels had fairly irregular shape of grain boundaries and inhomogeneous grain size, which suggested the contribution of somewhat discontinuous grain growth. This coarsening of ferrite would be responsible for the previously reported fact that $B$ addition lowers Lankford value of cold-rolled and annealed IF steel sheets.
\end{abstract}

KEY WORDS: hot compression; $\gamma-\alpha$ transformation; bainitic ferrite; polygonal ferrite; ferrite grain size; recrystallization; grain growth; texture; Lankford value; interstitial free steel; boron addition; microstructure.

\section{Introduction}

The importance of interstitial free (IF) steel has been increasing recently in the field of sheet steels. ${ }^{1,2)}$ In IF steels, titanium (Ti) or/and niobium $(\mathrm{Nb})$ are microalloyed to extra low carbon steel in order to scavenge interstitial solute atoms (carbon (C) and nitrogen (N)) by forming carbide and nitride. Being free from interstitials realizes excellent deep drawability and nonaging property. However, the lack of solute $\mathrm{C}$ and $\mathrm{N}$ weakens grain boundary, resulting in intergranular fracture in secondary working. ${ }^{1,2)}$ It has been clarified that addition of a small amount of boron (B) decreases ductile-brittle transition temperature and inhibits the secondary working brittleness. ${ }^{1-8)}$ The mechanism of suppressing secondary working embrittlement by $\mathbf{B}$ has been discussed and two possible mechanisms have been proposed: increased grain boundary bonding itself by segregated B and so-called site competition effect. ${ }^{8,9)}$ On the other hand, some reports showed that $\mathrm{B}$ addition lowers Lankford value ( $r$-value) of the cold-rolled and annealed IF steel sheet, ${ }^{10,11)}$ though the mechanism to decrease $r$-value has not been clarified yet.

Although texture control to improve deep-drawability of sheet steels is done in the cold-rolling and annealing process, the microstructure of the hot-rolled material largely affects the microstructure and texture of the final sheet. Especially, it is well known that fine ferrite grain in hot band is favorable to obtain highly developed $\{111\}$ texture with large $r$-value in the final sheet. ${ }^{12,13)}$ As is well-established, by the way, B is an element to segregate at austenite $(\gamma)$ grain boundaries and to increase hardenability of the steel by suppressing the nucleation of ferrite $(\alpha)$ at $\gamma$ grain boundaries. ${ }^{14)}$ Therefore, there is a possibility that also in IF steels $B$ addition affects $\gamma-\alpha$ transformation after hot rolling, in turn final texture and microstructure. As regards $\gamma-\alpha$ transformation and ferrite morphology, many investigations have been carried out in high strength type extra low carbon steels ${ }^{15,16)}$ but less studies have been conducted for plain IF steels. Therefore, whether B addition affects $\gamma-\alpha$ transformation in plain IF steels, and whether B increases or decreases ferrite grain size in hot band have not been fixed yet.

The purpose of the present study is to clarify the effect of B content and hot deformation on the ferrite structure of Ti-added IF steel by use of the steels with different amount of B. At first, effect of B addition on the microstructure of ferrite is to be clarified by nondeformation tests with various cooling rate from aus- 
ISIJ International, Vol. 37 (1997), No. 8

Table 1. Chemical composition of the materials studied. (mass $\%$ )

\begin{tabular}{|c|c|c|c|c|c|c|c|c|c|}
\hline & $\mathrm{C}$ & $\mathrm{Si}$ & $\mathrm{Mn}$ & $\mathrm{P}$ & $\mathrm{S}$ & $\mathrm{Ti}$ & $\mathrm{B}$ & sol.Al & $\mathrm{N}$ \\
\hline steel - I & 0.0031 & $<0.01$ & 0.15 & 0.010 & 0.005 & 0.049 & $<0.0001$ & 0.054 & 0.0018 \\
\hline steel - I & 0.0024 & $<0.01$ & 0.15 & 0.009 & 0.005 & 0.051 & 0.0005 & 0.054 & 0.0021 \\
\hline steel - II & 0.0029 & $<0.01$ & 0.14 & 0.009 & 0.005 & 0.049 & 0.0016 & 0.047 & 0.0017 \\
\hline steel - N & 0.0026 & $<0.01$ & 0.14 & 0.008 & 0.005 & 0.046 & 0.0024 & 0.015 & 0.0024 \\
\hline
\end{tabular}

tenite region. Then, hot-compression tests are to be done to clarify the effect of $B$ and deformation on ferrite structure of hot-deformed IF steel.

\section{Experimental}

Four kinds of Ti-added IF steels containing various amount of B was used in this study. Their chemical compositions are summarized in Table 1. Steel-I has no B, while steels-II, III and IV have different amount of B in the range of 5 to $24 \mathrm{wt} \mathrm{ppm}$. The steels were provided as hot-rolled sheets of $12 \mathrm{~mm}^{\mathrm{t}} \times 150 \mathrm{~mm}^{\mathrm{w}} \times 300 \mathrm{~mm}$. Cylindrical specimens of $8 \mathrm{~mm}^{\phi} \times 12 \mathrm{~mm}^{\mathrm{h}}$ were sparkmachined from the hot-rolled sheets.

Some of the specimens were provided to nondeformation tests. The specimens were austenitized at $1423 \mathrm{~K}\left(1150^{\circ} \mathrm{C}\right)$ for $1.2 \mathrm{ks}$, then cooled by $\mathrm{N}_{2}$ gas or water at a different cooling rate in the range of 0.1 to $500 \mathrm{~K} \mathrm{~s}^{-1}$.* Vickers hardness test and microstructural observations using an optical microscope (OM) or a transmission electron microscope (TEM) were carried out on the cooled specimens. Microstructure for OM was revealed by an etchant of $5 \%$ nital on the mechanically polished surface of the specimen. Thin foils for TEM observations were prepared by a twin-jet polisher using a $100 \mathrm{ml} \mathrm{HClO}_{4}+900 \mathrm{ml} \mathrm{CH}_{3} \mathrm{OH}$ solution. TEM observations were carried out by use of Hitachi $\mathrm{H}-800$ at $200 \mathrm{kV}$.

Hot-compression tests were done using a thermomechanical processing simulator (Thermecmastor-Z). The basic heat pattern is shown in Fig. 1. Specimens were heated to $1423 \mathrm{~K}$ at a heating rate of $20 \mathrm{~K} \mathrm{~s}^{-1}$ by a high frequency induction heating system, kept at $1423 \mathrm{~K}$ for $1.2 \mathrm{ks}$, quenched by $\mathrm{N}_{2}$ gas to deformation temperatures $\left(1223 \mathrm{~K}\left(950^{\circ} \mathrm{C}\right)\right.$ or $1323 \mathrm{~K}\left(1050^{\circ} \mathrm{C}\right)$; both in $\gamma$-region), compressed by $65 \%$ reduction in a strain rate of $0.1,1$, or $10 \mathrm{~s}^{-1}$ after holding for $5 \mathrm{~s}$ at the deformation temperature, and cooled by $\mathrm{N}_{2}$ gas at a cooling rate of $30 \mathrm{~K} \mathrm{~s}^{-1}$ immediately after deformation. As lubricants, both glass powders and thin plates of mica were used. Because the degree of barreling of the specimens was small enough, i.e., less than $15 \%$ in the cross-sectional area in every case, true stress and true strain were calculated under the assumption of homogeneous deformation. In order to clarify the effect of cooling rate after deformation on the microstructure of ferrite, some specimens deformed by $65 \%$ at $1223 \mathrm{~K}$ in a strain rate of $10 \mathrm{~s}^{-1}$ were cooled at $0.17 \mathrm{~K} \mathrm{~s}^{-1}$, or kept for $1.8 \mathrm{ks}$ at $973 \mathrm{~K}\left(700^{\circ} \mathrm{C}\right)$ in the course of cooling at $0.17 \mathrm{~K} \mathrm{~s}^{-1}$. The latter simulates the conventional coiling after hot rolling.

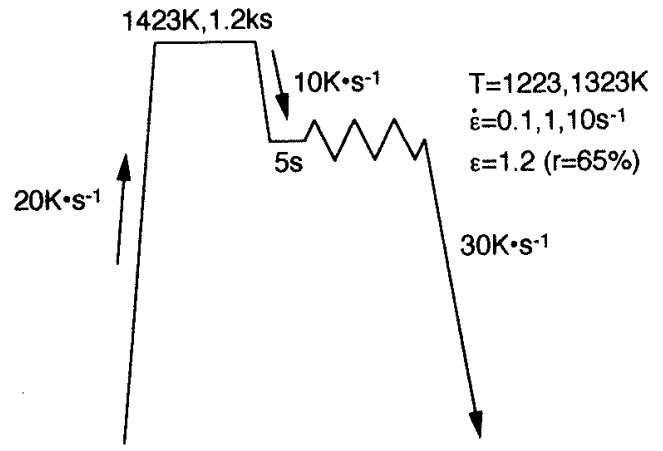

Fig. 1. Basic heat pattern for hot-compression tests.

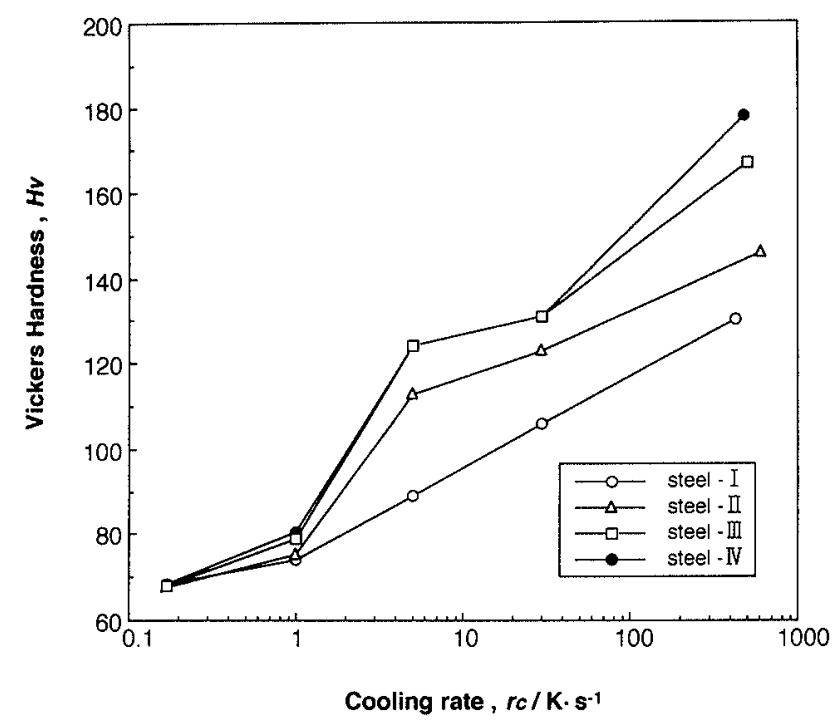

Fig. 2. Vickers hardness of the non-deformed specimens cooled at various cooling rate after austenitization at I $423 \mathrm{~K}$.

Vickers hardness test and microstructural observation by OM were carried out on the hot deformed specimens. All tests and observations were done in the center region on the section including the compression axis (CA). Ferrite grain size was measured on optical micrographs by intercepting method.

\section{Results}

\subsection{Non-deformed Specimens}

Figure 2 shows relationship between cooling rate from $1423 \mathrm{~K}$ and Vickers hardness of the non-deformed specimens. Hardness increases with increasing cooling rate. $B$ addition largely affects the curves. Hardness of the steels containing $B$ rapidly increases at lower cooling

* Cooling rates in this study were measured by a thermocouple welded on the side surface of the specimen. Strictly speaking, therefore, it indicates the cooling rate at surface, and that in the center region where microstructural observations were carried out is somewhat smaller. 

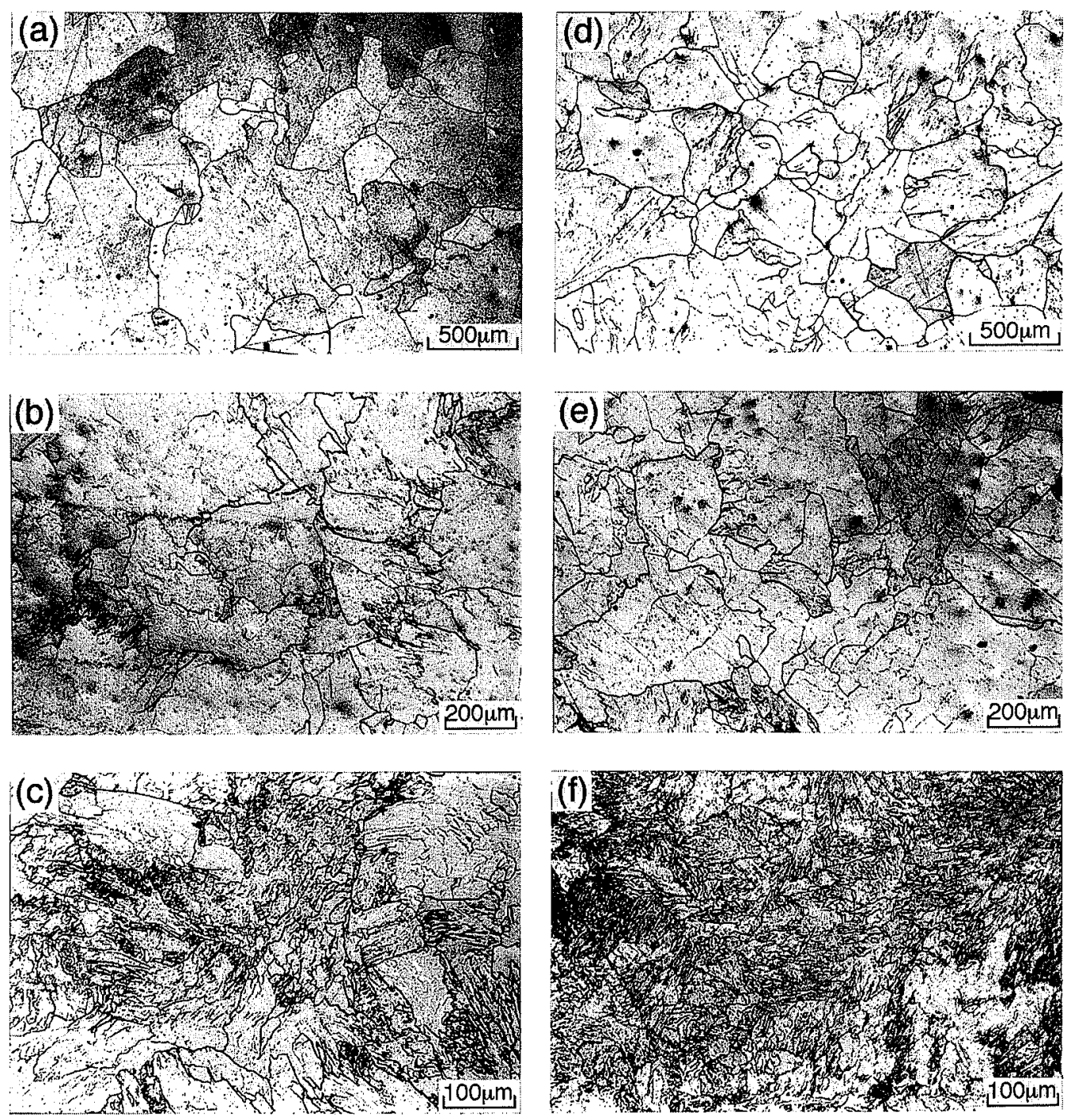

Fig. 3. Optical microstructures of steel-I $(a, b, c)$ and steel-III $(d, e, f)$ cooled at various cooling rate after austenitization at $1423 \mathrm{~K}$.

(a) $0.17 \mathrm{~K} \mathrm{~s}^{-1}$ cooled. (b) $5.0 \mathrm{~K} \mathrm{~s}^{-1}$ cooled. (c) $30 \mathrm{~K} \mathrm{~s}^{-1}$ cooled.

(d) $0.17 \mathrm{~K} \mathrm{~s}^{-1}$ cooled. (e) $1.0 \mathrm{~K} \mathrm{~s}^{-1}$ cooled. (f) $30 \mathrm{~K} \mathrm{~s}^{-1}$ cooled.

rate. Further, the hardness in the case of larger cooling rate increases with increasing $B$ content, though the curves of steel-III and steel-IV almost overlap. The change in hardness corresponds to the change in ferrite microstructure as will be shown later.

Figure 3 shows optical microstructures of steel-I and steel-III cooled from $1423 \mathrm{~K}$ at various cooling rates. The morphology of ferrite largely differs depending on the cooling rate. The most slowly cooled specimens show coarse and equiaxed ferrite (Figs. 3(a) and 3(d)). The size of the equiaxed ferrite decreases with increasing cooling rate, and the ferrite with fairly irregular shape appears (Figs. 3(b) and 3(e)). As cooling rate further increases, the ferrite with "acicular" morphology including substructures also appears (Figs. 3(c) and 3(f)). The fraction of "acicular" ferrite increases with increasing cooling rate and B content, which corresponds to the increase in Vickers hardness (Fig. 2) well. TEM micrographs corresponding to Fig. 3 are shown in Fig. 4. The most slowly cooled specimens show ferrite having equiaxed morphology with a small amount of dislocations (Figs. 4(a) and 4(d)). Figures 4(b) and 4(e), which correspond to the ferrite with irregular shape in $\mathrm{OM}$ (Figs. 3(b) and 3(e)), show the similar microstructures to Figs. 4(a) and 4(d). However, the grain boundaries have irregular shape. It was also observed in TEM observations of the specimens corresponding to Figs. 4(b) and 4(e) that the size of the ferrite was inhomogeneous and some of them showed elongated shape. The dislocation density inside the ferrite grain tends to increase with increasing cooling rate. The ferrite with the morphology completely different from those in the relatively slowly cooled specimens appears in Figs. 4(c) and 4(f). They show lath or plate like morphology with high dislocation density inside.

It is well-known that various transformation products can appear during continuous cooling of very low-carbon steels, and the terminology of the ferritic microstructures has been fairly confused. Araki et al. ${ }^{17-19)}$ have proposed the classification and terminology of the complex microstructures in low and ultra-low carbon steels. The major matrix phases they proposed are as follows ${ }^{15)}$ :

(i) polygonal ferrite $\left(\alpha_{\mathrm{p}}\right)$ : equiaxed, polyhedral shaped, mostly recrystallized. 

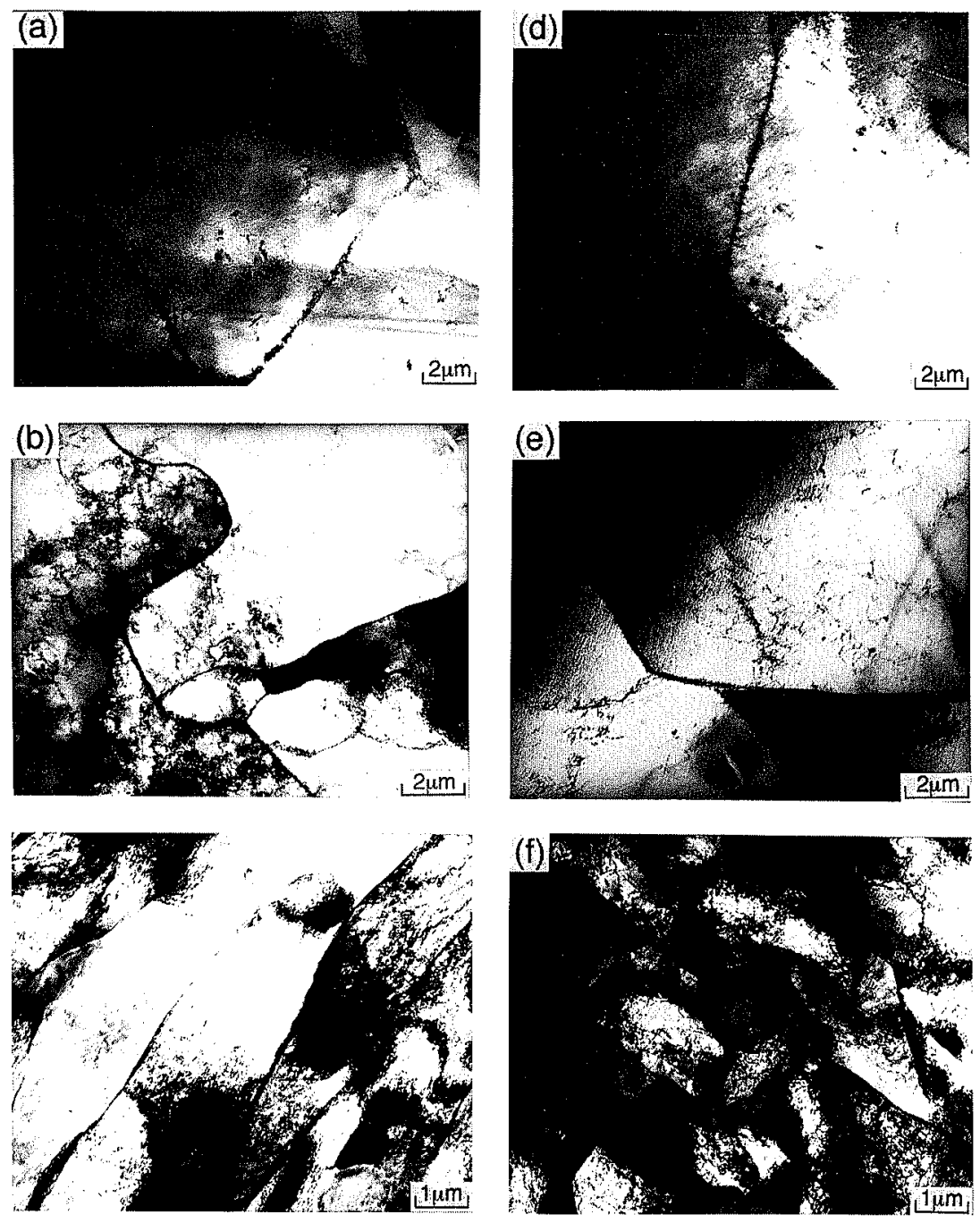

Fig. 4. TEM microstructures of steel-I (a, b, c) and steel-III (d, e, $f$ ) cooled at various cooling rate after austenitization at $1423 \mathrm{~K}$.

(a) $0.17 \mathrm{~K} \mathrm{~s}^{-1}$ cooled. (b) $5.0 \mathrm{~K} \mathrm{~s}^{-1}$ cooled. (c) $30 \mathrm{~K} \mathrm{~s}^{-1}$ cooled.

(d) $0.17 \mathrm{~K} \mathrm{~s}^{-1}$ cooled. (e) $1.0 \mathrm{~K} \mathrm{~s}^{-1}$ cooled. (f) $30 \mathrm{~K} \mathrm{~s}^{-1}$ cooled.

(ii) quasi-polygonal ferrite $\left(\alpha_{\mathrm{q}}\right)$ : irregular changeful shape, formed at lower temperature crossing over $\gamma$-grain boundary; mostly recovered.

(iii) Widmanstätten ferrite $\left(\alpha_{\mathrm{w}}\right)$ : characteristic lath/ plate-like shape; not usual in very low-C steels; mostly recovered.

(iv) granular bainitic ferrite $\left(\alpha_{\beta}\right)$ : granular bainitic ferritic $\mathrm{ZW}_{w}$ (Zwischen-stufe (intermediate stage)) structure; dislocated substructure but fairly recovered like "lath-less."

(v) bainitic ferrite $\left(\alpha_{13}^{0}\right)$ : sheaf-like with laths but no carbide; conserving the prior $\gamma$-grain boundary, generally enough dislocated.

(vi) dislocated cubic Martensite $\left(\alpha_{\mathrm{m}}^{\prime}\right)$ : lath type (massive) martensite; highly dislocated; conserving prior $\gamma$-grain boundary.

Because $\alpha_{w}$ is unusual in very low-C steels ${ }^{15}$ ) and it needs extremely large cooling rate more than $10^{3} \mathrm{~K} \mathrm{~s}^{-1}$ to obtain $\alpha_{\mathrm{m}}^{\prime}$ in highly pure iron, ${ }^{16)}$ it would be enough to consider the remaining four types of morphology, $\alpha_{\mathrm{p}}$, $\alpha_{\mathrm{q}}, \alpha_{\mathrm{B}}$ and $\alpha_{\mathrm{B}}^{0}$, in the present IF steels. The equiaxed ferrite observed in the slowly cooled specimens (Figs. $3(\mathrm{a})$ and $3(\mathrm{~d})$ ) is a typical $\alpha_{\mathrm{p}}$. The ferrite with irregular shape of grain boundary in Figs. 3(b) and 3(e) is $\alpha_{\mathrm{q}}$, though the TEM microstructures of it and its hardness are not so different from those of $\alpha_{p}$, as was shown before. The ferrite with lath or plate morphology in TEM (Figs. $4(c)$ and $4(f))$ and large hardness is a typical $\alpha_{\mathrm{B}}^{0}$. Though granular type ferrite with high dislocation density which may be classified as $\alpha_{B}$ was partly observed in the present TEM observations, there is a possibility that they are the sheaf of laths observed along longitudinal direction. ${ }^{20)}$ Anyhow, it can be concluded that the "acicular", ferrite in OM (Figs. 3(c) and 3(f)) is "bainitic ferrite" mainly composed of $\alpha_{\mathrm{B}}^{0}$.

Figure $\mathbf{5}$ is a morphology map of the present steels. The figure clearly shows that bainitic ferrite is easy to appear when the steel has $\mathrm{B}$.

\subsection{Hot-deformed Specimens}

Stress-strain curves of the steels in high temperature compression are shown in Fig. 6. Flow stress increases with decreasing deformation temperature and with increasing strain rate. In most cases $B$ addition scarcely affects the flow stress of austenite in IF steel, although in the case of $1223 \mathrm{~K}$ and $0.1 \mathrm{~s}^{-1}$ deformation only steel-I 


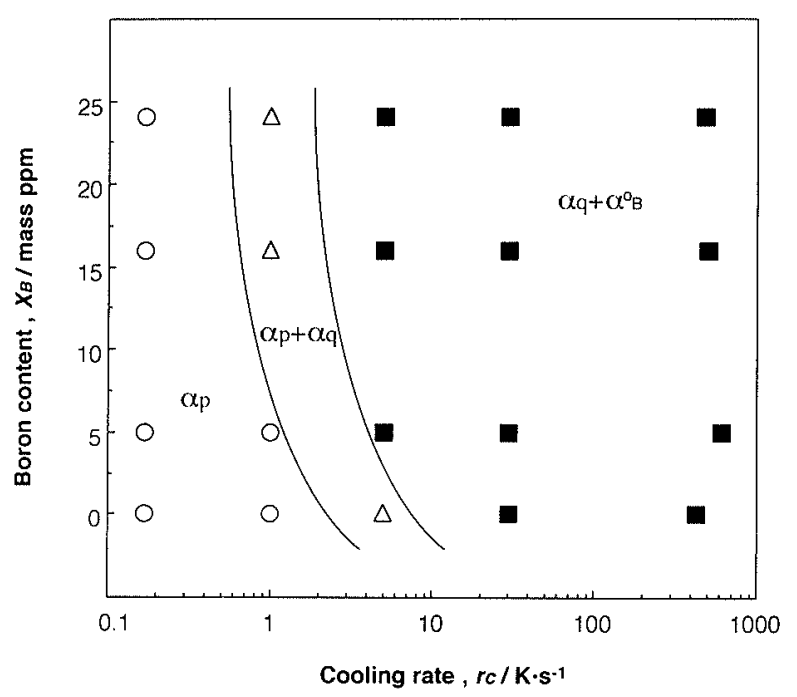

Fig. 5. Ferrite morphology map in the present steels cooled at various cooling rate after austenitization at $1423 \mathrm{~K}$.

shows a dynamic recrystallization type curve with a drop of stress. This suggests the possibility of inhibition of dynamic recrystallization by $\mathrm{B}$. It should be noted, however, that all steels show the dynamic recrystallization type curves in the case of $1323 \mathrm{~K}$ and $0.1 \mathrm{~s}^{-1}$ deformation (Fig. 6(a)).

Figures 7 and $\mathbf{8}$ show the ferrite microstructures of all steels compressed by $65 \%$ at a strain rate of $10 \mathrm{~s}^{-1}$ at 1223 and $1323 \mathrm{~K}$, respectively, and cooled at 30 $\mathrm{K} \mathrm{s}^{-1}$. Although the non-deformed specimens cooled at $30 \mathrm{~K} \mathrm{~s}^{-1}$ shows large fraction of bainitic ferrite as was shown in Figs. 3(c) and 3(f), the amount of bainitic ferrite decreases by hot deformation and $\alpha_{p}$ or $\alpha_{q}$ alternatively appears. Especially in the case of the steel without $B$ (steel-I), no bainitic ferrite is observed in the optical micrographs (Figs. 7(a), and 8(a)). Bainitic ferrite is rather easy to appear in the specimens deformed at higher temperature $(1323 \mathrm{~K})$. Not only the hot deformation but also the amount of $B$ largely affect the ferrite microstructure. That is, the amount of bainitic ferrite increases with increasing $\mathrm{B}$ content. However, small difference is observed between steel-III and steel-IV in the optical micrographs. Figure 9 shows ferrite grain size in each hot-deformed steel. This ferrite grain size means the size of $\alpha_{\mathrm{p}}$ or $\alpha_{\mathrm{q}}$. Therefore, it couldn't be determined in the specimens which is predominantly composed of bainitic ferrite. Ferrite grain size slightly decreases with increasing B content. Ferrite grain size in the $1223 \mathrm{~K}$ deformed specimens is smaller than that in the $1323 \mathrm{~K}$ deformed specimens. It should be kept in mind, however, that those results were obtained from the structures composed of not only $\alpha_{\mathrm{p}}$ or $\alpha_{\mathrm{q}}$ but also bainitic ferrite.

Corresponding to the change in morphology, hardness of the specimens changes with deformation condition and B content (Fig. 10). In Fig. 10, the hardness of the non-deformed specimens cooled at $30 \mathrm{~K} \mathrm{~s}^{-1}$ (the same cooling rate as that for the hot-deformed specimens) or $0.17 \mathrm{~K} \mathrm{~s}^{-1}$ (the slowest cooling rate in the present study) is superimposed. The non-deformed and slowly cooled $\left(0.17 \mathrm{~K} \mathrm{~s}^{-1}\right)$ specimens show the lowest hardness and their hardness is independent of $\mathrm{B}$ content. The non-
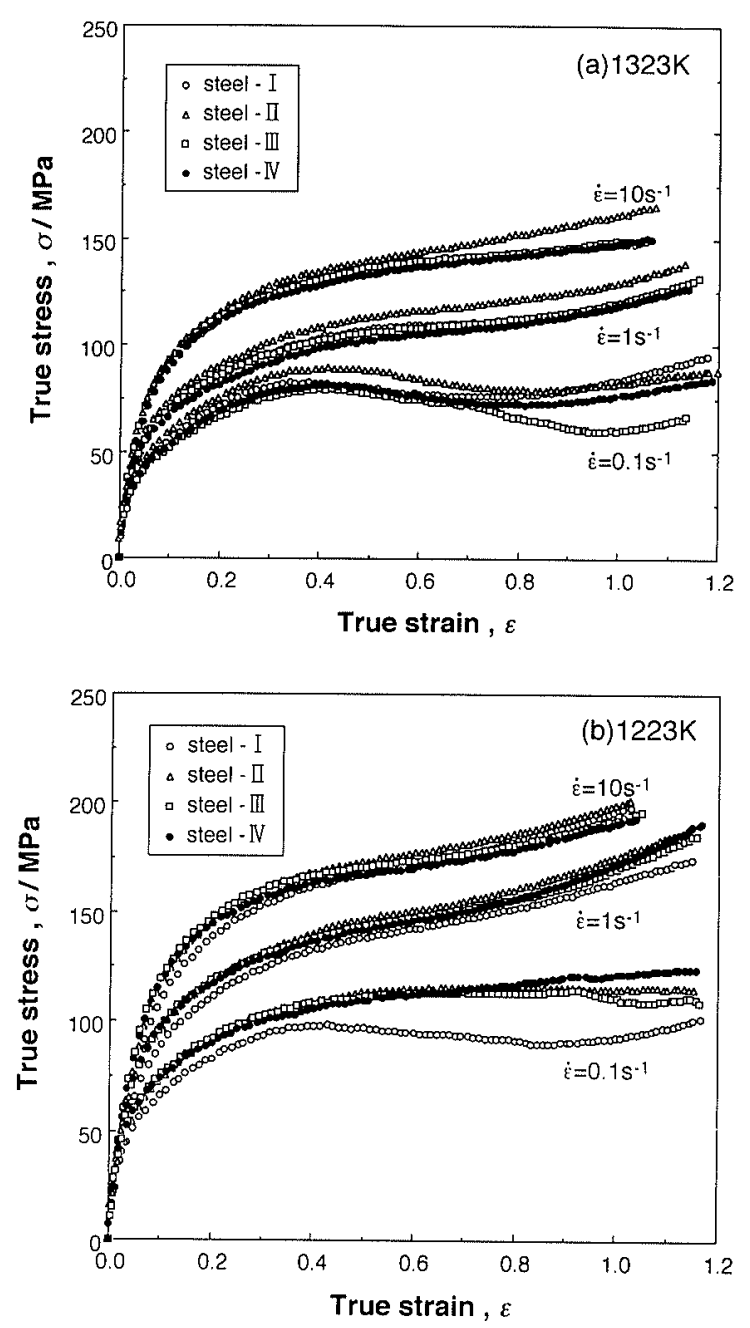

Fig. 6. Stress--strain curves of the specimens compressed at elevated temperatures.

deformed specimens cooled at $30 \mathrm{~K} \mathrm{~s}^{-1}$, on the other hand, show the highest hardness in the figure, and the hardness increases with increasing B content. In deformed specimens, hardness increases with increasing $B$ content. The increase in hardness by $B$ addition mainly corresponds to the amount of bainitic ferrite in the microstructure. The hardness of the steel-IV, however, is almost the same as that of the steel-III. Though the hot-deformed steel-I shows only $\alpha_{p}$ (Figs. 7(a) and 8(a)), the hardness of them is larger than that of the nondeformed and slowly cooled steel-I. It is presumably due to both the grain refinement of ferrite by hot-deformation and the progress in recovery within the ferrite grains in the slowly cooled specimens.

Optical microstructures of the specimens hot-deformed at $1223 \mathrm{~K}$ and $10 \mathrm{~s}^{-1}$, then cooled at $0.17 \mathrm{~K} \mathrm{~s}^{-1}$ are shown in Fig. 11. The coiling-simulated specimens showed nearly the same microstructures. All specimens show coarse $\alpha_{p}$. Contrary to the specimens rapidly cooled after deformation (Fig. 10), the grain size increases with increasing $B$ content as is summarized in Fig. 12 including the results of the coiling-simulation. The ferrite in the B containing steels is characterized by irregular shape of grain boundaries. In the B-containing steels, additionally, grain size distribution is fairly inhomogeneous, and some of the coarse and irregu- 

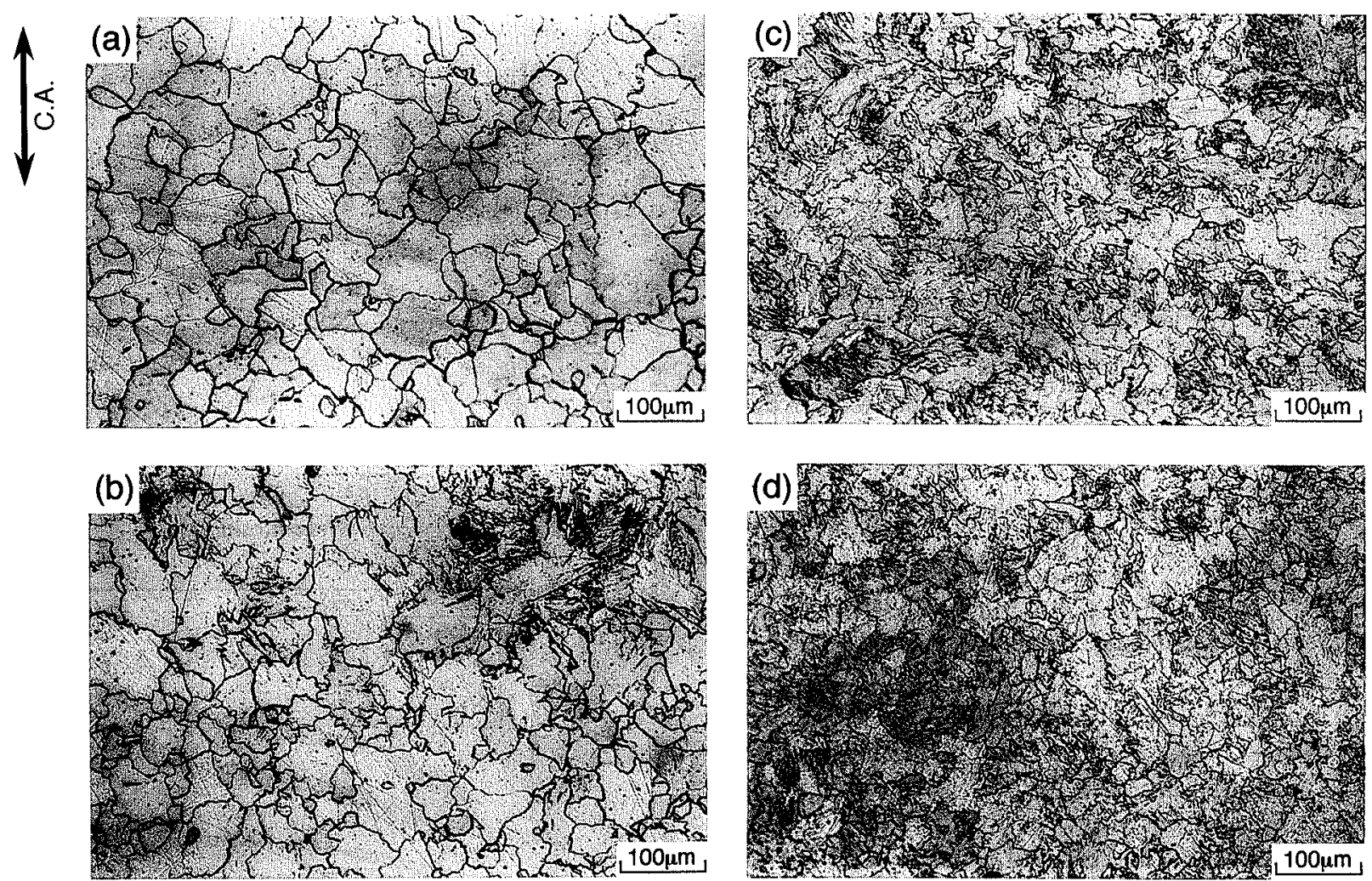

Fig. 7. Optical microstructures of the specimens compressed by $65 \%$ at $1323 \mathrm{~K}$ at a strain rate of $10 \mathrm{~s}^{-1}$, then cooled at $30 \mathrm{~K} \mathrm{~s}^{-1}$. On the section parallel to compression axis.

(a) steel-I. (b) steel-II. (c) steel-III. (d) steel-IV.
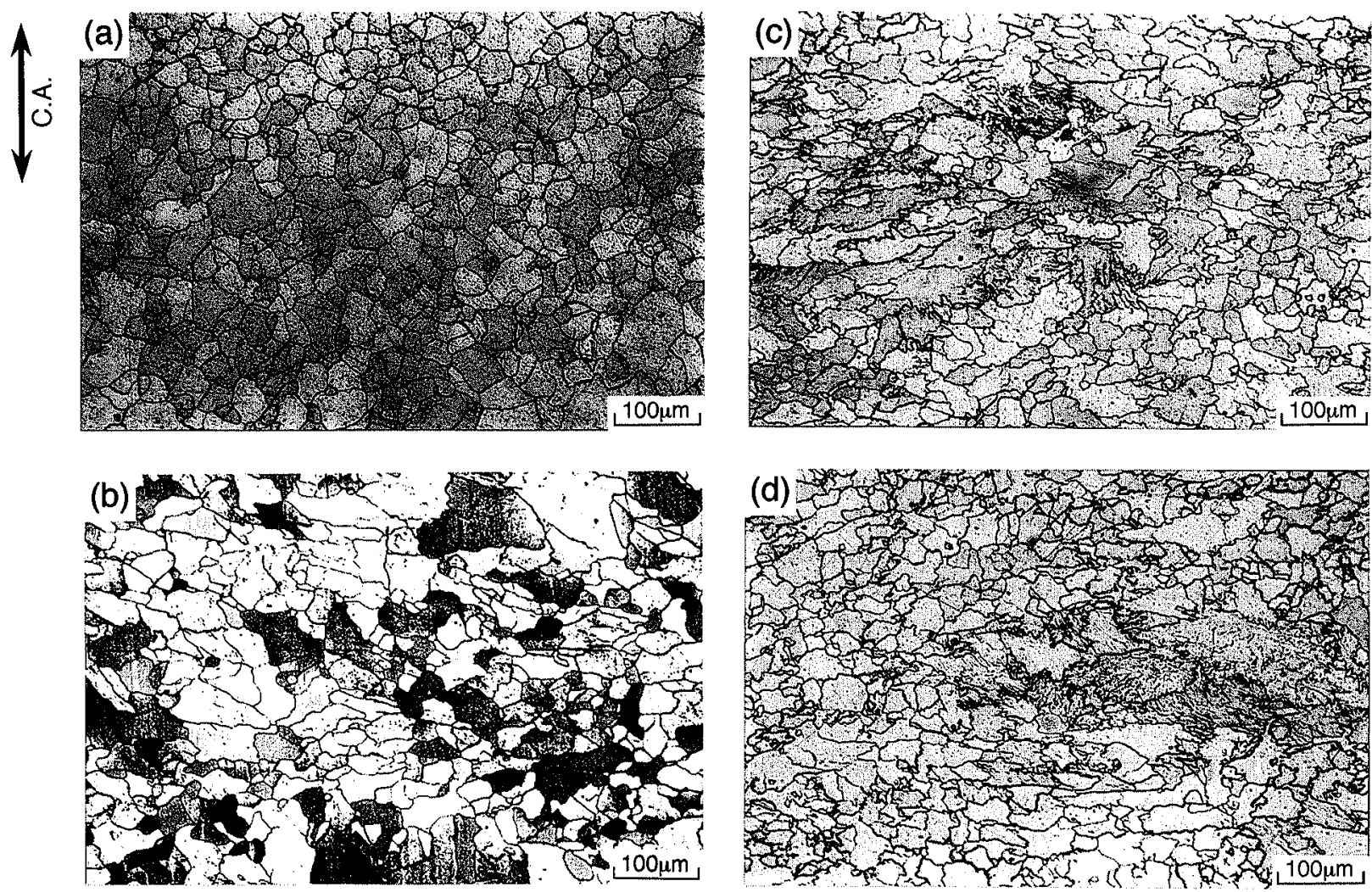

Fig. 8. Optical microstructures of the specimens compressed by $65 \%$ at $1223 \mathrm{~K}$ at a strain rate of $10 \mathrm{~s}^{-1}$, then cooled at $30 \mathrm{~K} \mathrm{~s}^{-1}$. On the section parallel to compression axis.

(a) steel-I. (b) steel-II. (c) steel-III. (d) steel-IV. 


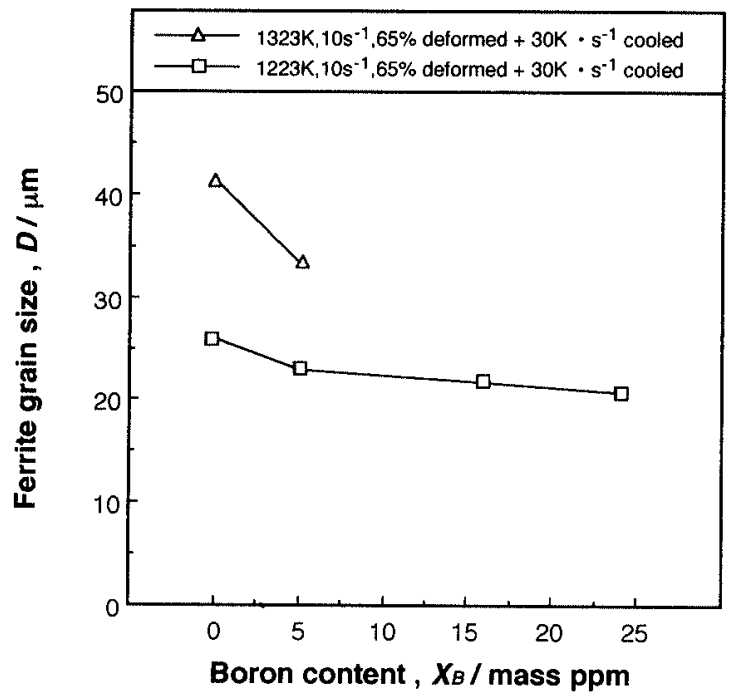

Fig. 9. Ferrite grain size in the hot-compressed and $30 \mathrm{~K} \mathrm{~s}^{-1}$ cooled specimens.
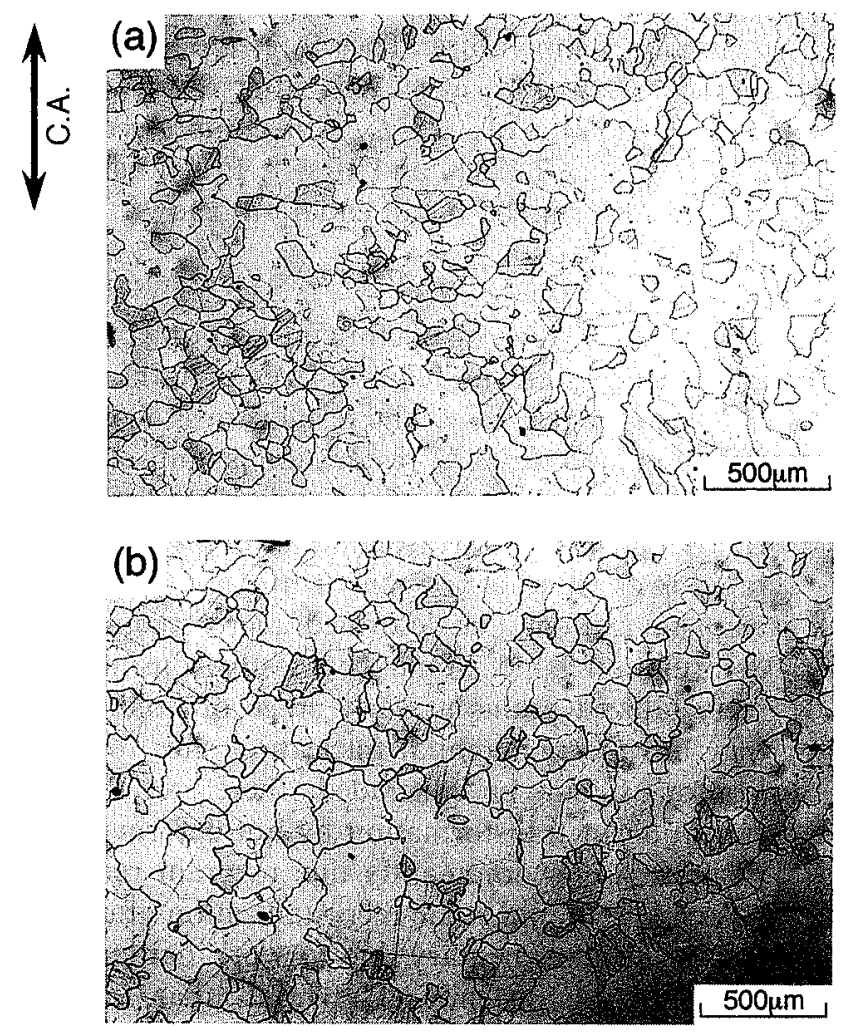
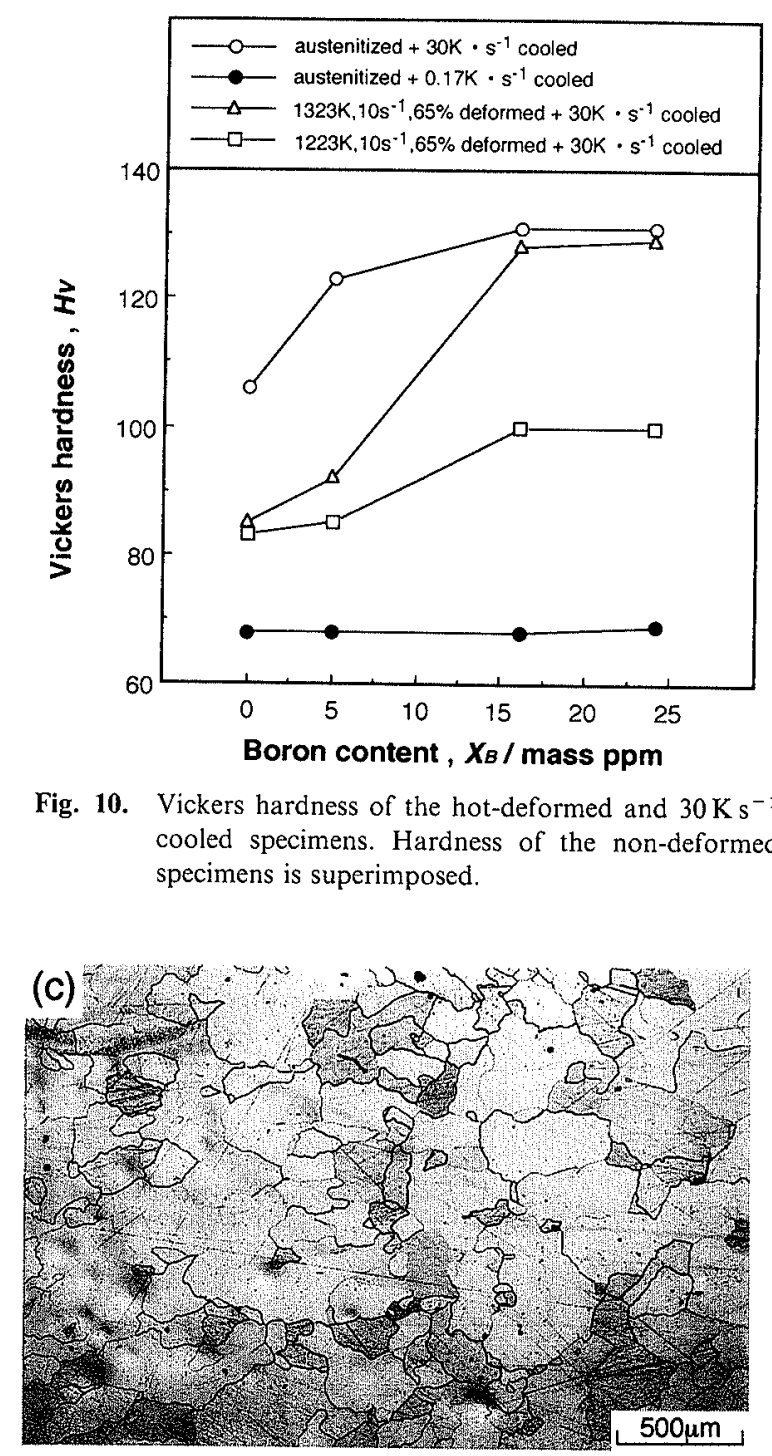

Fig. 10. Vickers hardness of the hot-deformed and $30 \mathrm{~K} \mathrm{~s}^{-1}$ cooled specimens. Hardness of the non-deformed specimens is superimposed.

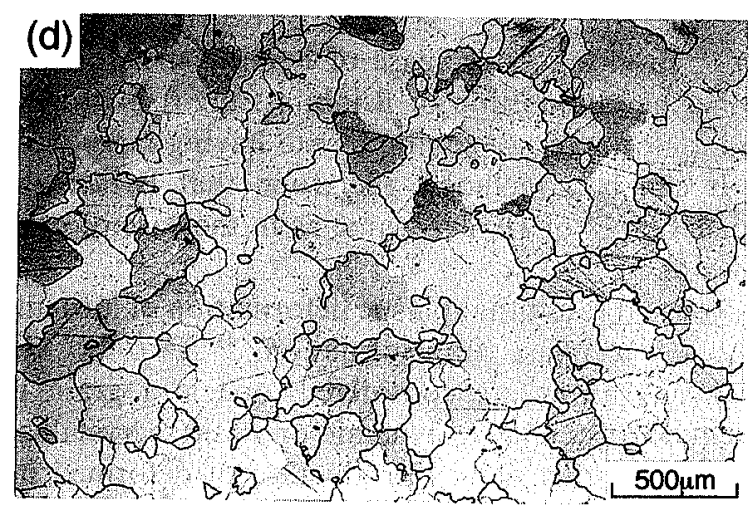

Fig. 11. Optical microstructures of the specimens compressed by $65 \%$ at $1223 \mathrm{~K}$ at a strain rate of $10 \mathrm{~s}^{-1}$ then cooled at $0.17 \mathrm{~K} \mathrm{~s}^{-1}$.

(a) steel-I. (b) steel-II. (c) steel-III. (d) steel-IV.

lar grains have slightly etched (maybe low-angle) boundaries within them.

\section{Discussions}

\subsection{Effect of B and Hot-deformation on $\gamma-\alpha$ Transforma- tion}

The present study clearly shows that bainitic ferrite having typically lath or plate morphology with high dislocation density can be obtained also in a plain IF steel by rapid cooling from austenite region. It was also clarified that both hot deformation and $\mathrm{B}$ addition largely affect the $\gamma-\alpha$ transformation and ferrite morphology of IF steel, as is schematically shown in Fig. 13. Hot deformation of austenite accelerates the formation of $\alpha_{p}$ 


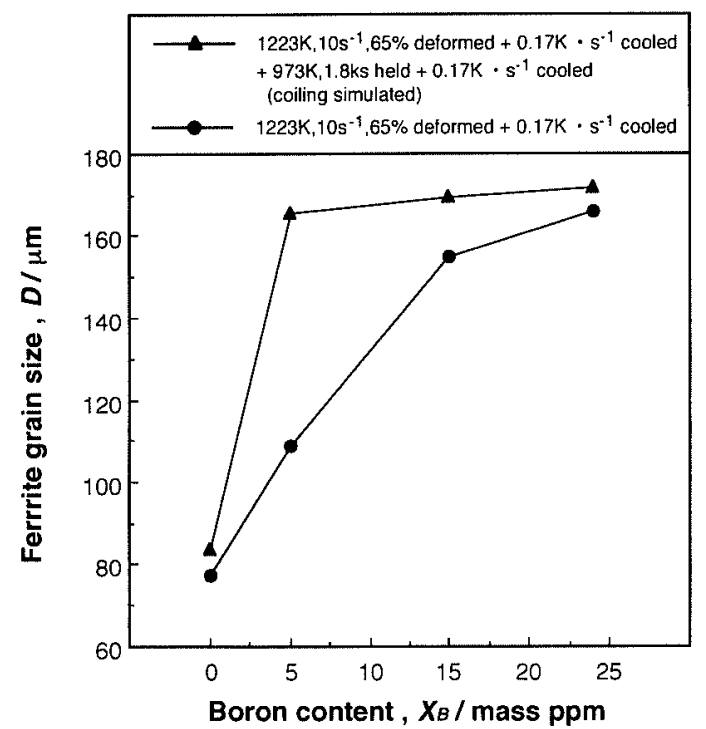

Fig. 12. Ferrite grain size in the hot-compressed and slowly cooled specimens.

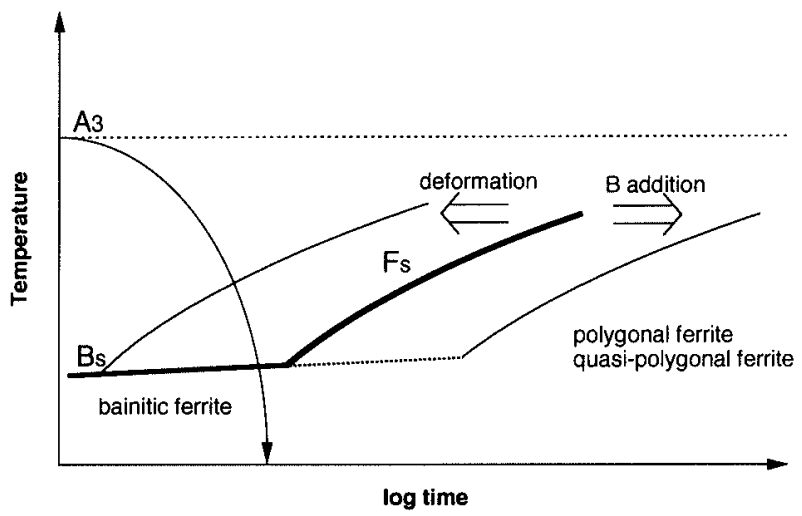

Fig. 13. Schematic illustration of the CCT diagram in the present IF steel.

and $\alpha_{q},{ }^{*}$ resulting in decrease of bainitic structure. On the other hand, addition of $B$ inhibits the formation of $\alpha_{p}$ and $\alpha_{q}$ to increase bainitic ferrite having large hardness. It can be concluded, therefore, that $B$ increases "hardenability" of IF steel same as in the case of other steels.

It is a usual result that plastic deformation of austenite enhances $\gamma-\alpha$ phase transformation. ${ }^{24)}$ Two possible mechanisms for it are considered: one is a grain refinement of austenite by dynamic or static recrystallization and the other is an introduction of deformed microstructures such as deformation band into austenite grains. ${ }^{24)}$ Although both mechanisms are commonly based on the increase in nucleation sites of ferrite (austenite grain boundary or deformed microstructure), it is important to distinguish them from the viewpoint to control the microstructure by thermomechanical processing. In order to clarify which mechanism is dominant in the present case, interrupting compression tests were simply done at $1223 \mathrm{~K}$ and $10 \mathrm{~s}^{-1}$. In this

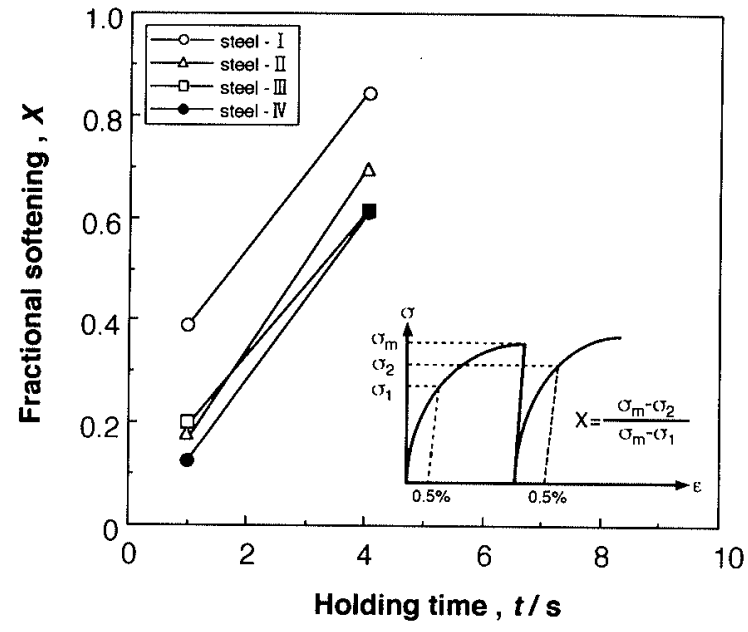

Fig. 14. Softening curves of the specimens after a compression by $65 \%$ at $1223 \mathrm{~K}$ at a strain rate of $10 \mathrm{~s}^{-1}$.

deformation condition, the stress-strain curves show work-hardening type ones (Fig. 6), which indicates no dynamic recrystallization occurs. Because the cooling rate after compression was $30 \mathrm{~K} \mathrm{~s}^{-1}$, it takes more than a few seconds before the specimen reaches the transformation temperature. Therefore, the specimens were hold for 1 or $4 \mathrm{sec}$ at $1223 \mathrm{~K}$ after $65 \%$ compression at a strain rate of $10 \mathrm{~s}^{-1}$, then compressed again by about $10 \%$ at $1223 \mathrm{~K}$ and $10 \mathrm{~s}^{-1}$. Fractional softening $(X)$ was determined by an equation below:

$$
X=\left(\sigma_{\mathrm{m}}-\sigma_{2}\right) /\left(\sigma_{\mathrm{m}}-\sigma_{1}\right)
$$

where $\sigma_{\mathrm{m}}$ is a stress just before interrupting deformation, and $\sigma_{1}$ and $\sigma_{2}$ are $0.5 \%$ proof stresses in the 1 st and the 2nd steps, respectively. The results are shown in Fig. 14. Time required for $50 \%$ restoration is quite short in each case: less than $2 \mathrm{sec}$ for steel-I and about $3 \mathrm{sec}$ for steelsII, III and IV. It is reasonable to consider that such a rapid restoration is not caused by only recovery but by recrystallization. The deformed microstructures such as deformation band would be mostly consumed by the recrystallized grains at early stage of holding because they are the preferential nucleation sites for recrystallization. It can be concluded, therefore, that the acceleration of transformation by hot-deformation in the present case is dominantly due to grain refinement of austenite by rapid static recrystallization after deformation and supplementary due to work hardening of unrecrystallized austenite. The result that the effect of deformation is rather smaller at higher temperature is thus reasonable, since the higher deformation temperature results in the smaller amount of work-hardening and the coarser recrystallized grains.

It is very noticeable, by the way, that the restoration rates of the steels-II, III and IV are smaller than that of the steel-I in Fig. 14. This suggests that addition of B suppresses static recrystallization of austenite. Though the effect of $B$ on $\gamma-\alpha$ transformation in steels has been

* Although the hot deformation of austenite would accelerate not only the start of transformation to $\alpha_{\mathrm{p}}$ and $\alpha_{\mathrm{q}}$ but also that to bainitic ferrite, ${ }^{21,22)}$ the shift of Bs line is omitted in Fig. 13. This is because the Bs line is thought to be nearly parallel to the $x$-axis in the range of present cooling rate. $^{23)}$ 
well-known, little has been studied on the effect of B on recrystallization. This interesting effect should be minutely investigated in the future.

$B$ has a large effect on $\gamma-\alpha$ transformation even in IF steel. In the IF steels containing $B$, bainitic ferrite is easy to appear. To make the structure of the hot band bainitic may be practically important because Matsumoto et al. ${ }^{23)}$ and Ikeda et $a .^{25)}$ showed that the bainitic structure before cold rolling strengthens $\{111\}$ texture in final annealed sheet of extra-low carbon steels. In actuality, however, it may be difficult to obtain the hot band with bainitic ferrite through usual processing route, because total reduction is very large in hot-strip mills and the cooling rate after hot rolling is small. As Matsumoto et $a .^{23)}$ showed, rapid cooling after rolling and low temperature coiling might make it possible to obtain bainitic ferrite structure after hot rolling in B-added IF steel. Actually, we have clarified in a parallel investigation that bainitic ferrite can be obtained in the present B-bearing IF steels rapidly cooled after high-speed hot-rolling. ${ }^{26)}$ The present study indicates that small amount of work-hardening, i.e., high deformation temperature is favorable to decrease the acceleration of $\gamma-\alpha$ transformation by hot-deformation to result in bainitic ferrite.

It is noteworthy, additionally, that the change in hardness, microstructure and ferrite grain size by addition of $B$ seems to saturate at about 16 ppm $B$, that is, the results in steel-IV are almost the same as those in steel-III. According to $\mathrm{Fe}-\mathrm{B}$ binary alloy phase diagram, ${ }^{27)}$ the solubility of $B$ in austenite at $1423 \mathrm{~K}$ is more than $150 \mathrm{ppm}$, while it largely decreases to less than $10-20 \mathrm{ppm}$ at about $1130 \mathrm{~K}$. The extra boron can precipitate during cooling. The present results suggest that the precipitation of $B$ rapidly occurs and only solute $B$ affects the $\gamma-\alpha$ transformation. However, it can not be concluded that the addition of $B$ above $16 \mathrm{ppm}$ is meaningless, because the precipitation behavior is largely affected by cooling rate after austenitization or hot-deformation. Actually, though the cooling rate of $30 \mathrm{~K} \mathrm{~s}^{-1}$ was most frequently used in the present study, the hardness of steel-IV was larger than that of steelIII when $500 \mathrm{~K} \mathrm{~s}^{-1}$ cooled (Fig. 2).

\subsection{Effect of B on Ferrite Grain Size}

It was clarified in the present study that the addition of $\mathrm{B}$ also affects ferrite grain size in hot-deformed materials, which is very important because ferrite grain size in hot band affects final texture of the sheet. ${ }^{12)}$ It is noticeable that the tendency of effect of $B$ is different between the rapidly cooled specimens and the slowly cooled specimens: in the case of rapid cooling, the grain size of $\alpha_{\mathrm{p}}$ and $\alpha_{\mathrm{q}}$ slightly decreases with increasing $\mathrm{B}$ content (Fig. 9), while it reverses in the case of slow cooling (Fig. 12).

Attention should be paid to the data in Fig. 9, since the rapidly cooled specimens also have bainitic ferrite. However, the data in the case of $1223 \mathrm{~K}$ deformation is much reliable because the $1223 \mathrm{~K}$ deformed specimens have a small amount of bainitic ferrite (Fig. 8). The effect of $B$ on grain size in the case of rapid cooling can be explained by lowering transformation temperature by $\mathrm{B}$ as was schematically shown in Fig. 13. Lowering temperature increases the driving force for transformation to ferrite and results in refinement of the ferrite. ${ }^{28}$ ) Additionally, the inhibition of static recrystallization of austenite after hot deformation (Fig. 14) would make the ferrite fine by enhancement of transgranular nucleation.

It is clear, on the other hand, that ferrite grain size increases with increasing $B$ content in the case of slow cooling. This is one of the most important results in this study because it might be the reason why $\mathrm{B}$ addition lowers $r$-value of cold-rolled and annealed IF steel sheets. There are two possible mechanisms for grain coarsening by $B$ addition: one is the suppressing nucleation of ferrite due to B segregated at $\gamma$ grain boundaries, and the other is the grain growth of ferrite after transformation. Both the microstructural features in Fig. 11 and the fact that the grain size slightly decreased by $B$ addition in the case of rapid cooling (Fig. 9) suggest that the coarsening is very likely caused by the grain growth. It should be noted that the microstructural features of the B-bearing steels in Fig. 11, i.e., inhomogeneous grain size and irregular shape of grain boundaries, are similar to those resulted from abnormal grain growth. This indicates the occurrence of somewhat discontinuous grain growth.

Solute B has been thought to segregate also at ferrite grain boundary. Segregated elements inhibit the migration of grain boundary by solute drag effect, ${ }^{29.30)}$ which is contradictory to the present result. Additionally, it is hard to imagine that the segregated B atoms which can easily diffuse in grain boundary pins the particular points of grain boundary like in Fig. 11. Fe-B phase diagram $^{27)}$ shows that the solubility of $B$ in ferrite is very small. It shows the maximum value of $40-80 \mathrm{ppm}$ at about $1183 \mathrm{~K}\left(910^{\circ} \mathrm{C}\right)$ and rapidly decreases with decreasing temperature (for example, less than $10 \mathrm{ppm}$ at $\left.973 \mathrm{~K}\left(700^{\circ} \mathrm{C}\right)\right)$. Therefore, supersaturated $\mathrm{B}$ would precipitate as iron-boride and/or iron-borocarbide* during slow cooling. ${ }^{31)}$ Precipitates also pin the grain boundary by Zener drag effect. ${ }^{29.30)}$ However, if the B-precipitates coarsen, the boundaries released from the pin would rapidly move under the reserved large driving force for grain growth. This is one of the mechanisms of abnormal grain growth. The observed low-angle boundary within individual coarse grain suggests that the coarse grain was formed by the coalescence of some grains with similar orientation. The orientational factor might also affect the discontinuous grain growth, and resulting texture as well as coarsening of ferrite might be also one of the reasons why B-added IF steels show lower $r$-value in final sheets. ${ }^{10,11)}$ The speculated mechanism for effect of B on grain coarsening, anyway, should be inspected in the following study.

As regards the effect of $B$ on ferrite grain size, the opposite results have been proposed in laboratory experiments. Tsukatani ${ }^{10)}$ showed that the grain size

\footnotetext{
* Although B tends to form nitride (BN), BN is thought to be hard to appear in the present steels containing Ti which is a stronger nitride former.
} 
in hot band increases by addition of $\mathrm{B}$ in a Ti-added extra low carbon steel. On the other hand, Hosoya et $a l .{ }^{32)}$ reported the grain refinement by $\mathrm{B}$ addition in a hot-deformed $\mathrm{Nb}$-added IF steel. Tanigawa et al. $^{33)}$ also reported the refinement by $B$ in the case of low finishing temperature of hot rolling in a Ti-added IF steel. Hosoya et $\mathrm{al}^{32)}$ took a relatively high cooling rate $\left(20 \mathrm{~K} \mathrm{~s}^{-1}\right)$ after hot-deformation, ${ }^{*}$ therefore their result coincides with the present one in the case of rapid cooling $\left(30 \mathrm{~K} \mathrm{~s}^{-1}\right.$; Fig. 9). The present investigation suggests that, at least in Ti-added plain IF steel, B addition would increase ferrite grain size in the hot bands produced by conventional processing having large amount of total hotreduction and high coiling temperature (low cooling rate). It should be emphasized again that this coarsening effect of $\mathrm{B}$ would be responsible for the lowering $r$-value in the final sheets. The present results also indicate that the effect of B on ferrite structure is very sensitive to the various experimental factors, such as chemical composition, deformation temperature, reduction in deformation and cooling rate before/after $\gamma-\alpha$ transformation, which may be the reason why the opposing results were reported in the laboratory investigations. ${ }^{0,32,33)}$

\section{Conclusions}

Effect of B addition and hot-deformation of austenite on microstructure of ferrite has been studied using Ti-added IF steels containing different amount of $B$. The major results are as follows.

(1) Bainitic ferrite having typically lath or plate morphology with high dislocation density can be obtained also in the plain IF steel by rapid cooling after austenitization. $\mathrm{B}$ addition largely affects the $\gamma-\alpha$ transformation. The amount of bainitic ferrite and the hardness increase with increasing $\mathbf{B}$ content. That is, $\mathrm{B}$ increases bainitic hardenability in IF steels.

(2) Hot-deformation of austenite enhances the transformation to polygonal or quasi-polygonal ferrite, resulting in decrease of bainitic ferrite. This effect is more remarkable in the case of lower temperature deformation. Enhanced transformation by hot-deformation is mainly due to grain refinement of austenite by static recrystallization. $\mathbf{B}$ addition retards the static restoration of austenite after hot-deformation.

(3) When the materials are cooled rapidly after hotdeformation, ferrite grain size slightly decreases with increasing B content. Conversely, ferrite grain size largely increases with increasing $B$ content in the case of slow cooling. The ferrite in the slowly cooled specimens shows characteristically irregular shape of grain boundaries and inhomogeneous grain size. This coarsening of ferrite by $B$ addition would be one of the reasons why $B$ addition lowers Lankford value in the final sheets.

\section{Acknowledgements}

The steels used in this study were prepared by Sumitomo Metal Industries Ltd. as common samples for Recrystallization and Texture Research Committee in
ISIJ, and the authors appreciate Professor Taku Sakai of University of Electrocommunication (chairman of the committee) and other committee members for their helps and discussions.

\section{REFERENCES}

1) H. Takechi: ISIJ Int., 34 (1994), I.

2) K. Sakata: Advanced Technology of Microstructural Control in Steel and Titanium, the 161st and the I62nd Nishiyama Memorial Lecture, ISIJ, Tokyo, (1996), 83.

3) N. Takahashi, M. Shibata and Y. Furuno: Tetsu-to-Hagané, 66 (1980), S1127.

4) T. Suda, M. Sakamaki, K. Tayama, K. Araki, M. Wada and H. Kajitani: Tetsu-to-Hagané, 69 (1983), SI365.

5) M. Yamada, Y. Tokunaga and M. Yamamoto: Tetsu-to-Hagané, 73 (1987), 1049.

6) H. C. Chen and Y. S. Hwang: CAMP-ISIJ, 4 (199I), 1939.

7) Y. Maehara and N. Mizui: Physical Metallurgy of IF Steels, ISIJ, Tokyo, (1993), 233.

8) E. Yasuhara, K. Sakata, T. Kato and O. Hashimoto: ISIJ Int., 34 (1994), 99

9) C. M. Liu, T. Nagoya, K. Abiko and H. Kimura: Metall. Trans. $A$, 23A (1992), 263.

10) I. Tsukatani: Tetsu-to-Hagané, 75 (1989), 774

11) H. C. Chen and Y. S. Hwang: CAMP-ISIJ, 5 (1992), 2042

12) M. Abe, Y. Kokabu, Y. Hayashi and S. Hayami: Trans. Jpn. Inst. Met., 23 (1982), 718.

13) T. Yamada and M. Oda: CAMP-ISIJ, 5 (1992), 2045.

14) R. W. K. Honeycombe and H. K. D. H. Bhadeshia: Steels, Edward Arnold, London, (1995), 163.

15) Atlas for Bainitic Microstructures, Vol. 1, ISIJ, Tokyo, (1992).

16) T. Maki: Proc. of the Int. Forum for Physical Metallurgy of IF Steels, ISIJ, Tokyo, (1994), 183.

17) T. Araki, K. Shibata and M. Enomoto: Proc. of the Int. Conf. on Martensitic Transformations (ICOMAT-89), ed. by B. C. Muddle, Trans. Tech. Pub., VT, USA, (1989), 275.

18) T. Araki, M. Enomoto and K. Shibata: Mater. Trans. JIM, 32 (1991), 729.

19) T. Araki, K. Shibata and H. Nakajima: Proc. of the Int. Conf. on Martensitic Transformations (ICOMAT-92), ed. by C. M. Wayman and J. Parkins, Monterey Inst. of Advanced Studies, CA, USA, (1992), 767.

20) K. Tsuzaki: private communication.

21) K. Tsuzaki, T. Ueda, K. Fujiwara and T. Maki: Proc. of the 1st Japan Int. SAMPE (Soc. for Advancement of Mater. and Process Eng.) Symp., Soc. for Advancement of Mater. and Process Eng., Chiba, Japan, (1989), 699.

22) K. Fujiwara and S. Okaguchi: Tetsu-to-Hagané, 80 (1994), 771.

23) T. Matsumoto, S. Hamanaka, T. Yamada and T. Tanaka: Proc. of the Int. Forum for Physical Metallurgy of IF Steels, ISIJ, Tokyo, (1994), 269

24) T. Maki and I. Tamura: J. Jpn. Soc. Technol. Plast., 25 (1984), 772.

25) N. Ikeda, K. Tsuzaki and T. Maki: CAMP-ISIJ, 8(1995), 1384.

26) T. Sakai, T. Adachi, N. Tsuji and Y. Saito: CAMP-ISIJ, 9 (1996), 1331.

27) M. Hansen: Constitution of Binary Alloys, 2nd ed., McGraw-Hill, New York, (1958), 249.

28) T. Maki: Netsu Shori (J. Jpn. Soc. Heat Treat.), 29 (1989), 278.

29) T. Nishizawa: Tetsu-to-Hagané, 70 (1984), 1984.

30) T. Maki: the 143rd and the 144th Nishiyama Memorial Lecture, ISIJ, Tokyo, (1992), 51.

31) K. A. Taylor: Metall. Trans. A, 23A (1992), 107.

32) Y. Hosoya, T. Hashimoto and A. Nishimoto: Physical Metallurgy of IF Steels, ISIJ, Tokyo, (1993), 179.

33) K. Tanigawa, Y. Hosoya and A. Nishimoto: Physical Metallurgy of IF Steels, ISIJ, Tokyo, (1993), 170.

* The cooling rate after hot rolling in the case of Tanigawa $e t a l .{ }^{33)}$ is not clear. 